\title{
Tectonic thinking in contemporary industrialized architecture
}

\author{
Anne Beim* \\ CINARK - Centre for Industrialized Architecture, Institute of Architectural Technology, The Royal Danish \\ Academy of Fine Arts - School of Architecture, Copenhagen, Denmark
}

Received: 6 June 2013

Accepted: 16 October 2013

\begin{abstract}
This paper argues for a new critical approach to the ways architectural design strategies are developing. Contemporary construction industry appears to evolve into highly specialized and optimized processes driven by industrialized manufacturing, therefore the role of the architect and the understanding of the architectural design process ought to be revised. The paper is based on the following underlying hypothesis: 'Tectonic thinking - defined as a central attention towards the nature, the properties, and the application of building materials (construction) and how this attention forms a creative force in building constructions, structural features and architectural design (construing) - helps to identify and refine technology transfer in contemporary industrialized building construction'. ${ }^{1}$

Through various references from the construction industry, business theory and architectural practice the paper offers various analyses, comparisons and concrete design approaches. How architectural design processes and the tectonic design can benefit from Integrated Product Deliveries, mass-customization and Design for Disassembly is examined and discussed. The paper concludes by presenting a series of arguments that call for adaptable systems based on sufficient numbers of industrialized building products of high quality and a great variety of suppliers, and point at the need for optimizing our use of resources in order to reach sustainable solutions in architecture.
\end{abstract}

Keywords: Architectural design, facade design, design, construction, construction industry, building envelopes, facades, residential building, standards, sustainable development, project management, environmental impact, life-cycle

\section{Introduction}

When speaking about the future demands for industrialized architecture - or how to translate industrialized processes into tectonic sustainable design strategies in architecture - several questions come to mind.

First of all, why is the building industry in comparison to the production industry of consumer goods, apparently developing slowly in terms of incorporating new technologies, products and practices? Secondly, which general obstacles can be identified - and finally what are the potentials, which seem to be embedded in knowledge production of related industries and professions?

\footnotetext{
${ }^{*}$ Corresponding author: Professor Anne Beim, Ph.D., CINARK - Centre for Industrialized Architecture, Institute of Architectural Technology, The Royal Danish Academy of Fine Arts - School of Architecture, Phillip Langes ALlé 10, DK-1435 Copenhagen, Denmark. Tel.: +45 4170 1623; E-mail: anne.beim@kadk.dk.

${ }^{1}$ This definition of tectonic thinking forms part of a large, central research project: Towards a tectonic sustainable building practise, that is presently (2010-2014) executed in collaboration between; The Royal Danish Academy of Fine Arts - School of Architecture, Aarhus School of Architecture, and The Danish Building Research Institute.
} 
Although these questions raise a widespread discussion, one could argue that the building industry can benefit from different ways of architectural synthesis thinking as a basis for improving. This understood in such a way that industrialized manufacturing technologies and products should be driven by ideas and innovation, which enrich and improve the building designs - the architecture - both in terms of customization when manufactured, adaptability, sustainable solutions and aesthetics. In the following, this series of questions and arguments will be further analyzed and discussed primarily in order to address the heading of this article, but also quite importantly in order to test the underlying hypothesis that: Tectonic thinking can be used as an explicit design strategy.

\subsection{The meaning of industrialization in contemporary building industry}

If we look at contemporary building industry, it is generally characterized by a great number of parallel domains of knowledge, technologies and practices. Due to this fundamental condition, it holds a series of insoluble, but also interesting paradoxes. Today's building industry, embraces highly advanced levels of technologies yet one can find construction practices and technical solutions that have not changed noticeable for many centuries. To exemplify, nano technology used for improving the properties of glazing surfaces can be built into a structure next to traditional stone masonry. Similar to other manufacturing industries that provide for fundamental human needs, the building industry is resting on the shoulders of previous technologies and traditions of manufacture. As such, the building industry is rooted in the crafts, practices and codes of conduct that arise from particular economies, societal systems and cultural settings. Layers of improved technologies are continuously added and the use of new materials and manufacturing procedures are expanding the existing fields of knowledge and practices. It is therefore predominantly characterized by forming an evolutionary track. Only rarely we see radical changes - or significantly new methods and technologies implemented 'over night' in the building industry. As Strike notes some of the most inventive ideas in terms of improving building technology that have informed and changed the building industry have been envisioned by architects. This influence was in particular prevailing in the late 19th and 20th centuries.

Due to its heterogeneous and 'slow-moving' nature, the building industry is often mentioned for its lack of true technological sophistication and for its shortcomings in terms of productivity, when compared to other industries of consumer products - the car industry or ship building industry in particular. For the past century, the car industry and ship building industries have been pointed out as comparable industries, when speaking about productivity and future manufacturing for buildings. However, this idea is usually argued for from an economically point of view - not taking into account that buildings are fundamentally different being prototypes, grounded on a specific site, rooted in a cultural and societal context, as well as they are planned to last for decades or maybe centuries. Due to these critical differences, the car industry and ship building industries do NOT seem sufficient models for the building industry.

However, these conclusions are not truly valid. The poor reputation partly has to do with statistical logics of categorization. When building trades grow to be industrialized, e.g. the window industry, they usually move from the building industry category to the product industry category (at least in the Danish statistical systems). In that sense, the statistical records of the building industry will always bear the mark of 'the poor performative parts' that seems to remain: The complex inter-disciplinary fields of knowledge that have to collaborate on the building designs/execution and issues that concerns procedures on the site, will always seem insufficient in regard of conventional economical productivity, and will always figure in the statistics. 


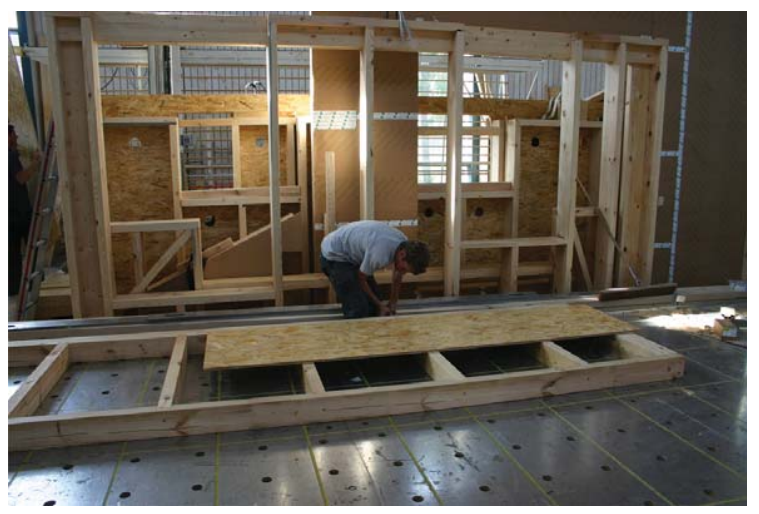

Fig. 1. Wall assembly at the Berchtold Holzbau factory in Voralberg.

There is no doubt that the building industry has developed significantly in terms of industrialized manufacturing. In particular, the introduction of digital technologies has provided new and different ways of fabrication through the past couple of decades. These new digital technologies make long series of identical objects unnecessary, industrially manufactured components can be unique, and optimized to fit a particular construction design (Fig. 1). This counts both for smaller objects and large scale; including advanced production of integrated building components; complex volumetric building elements as well as different sorts of all-encompassing construction solutions. In addition, a great number of building practices including various trades at the construction site have become more 'automized' and have been developed into more efficient fabrication procedures by use of mechanized tools and gear that improve the execution of the physical construction as demonstrated by Kieran \& Timberlake (2004).

\section{Mass production - mass customization - custom made}

Inspired by a tendency in the product industry contemporary building industry is slowly moving from an 'old-fashioned' manufacturing concept of Mass Production - to a more flexible manufacturing concept of Mass Customization. Where mass production primarily is directed towards an economical logic of efficiency of organization and mechanical manufacturing procedures, which depends on standardization, repetition, reduction of variables, and a market of 'anonymous masses' (Taylorism). ${ }^{2}$ Mass customization is rather based on a consumer oriented economical rationale, making use of

\footnotetext{
2"Taylorism was a theory of management that analyzed and synthesized workflows. Its main objective was to improve economic efficiency, especially labor productivity. It was one of the earliest attempts to apply science to the engineering of processes and to management. Its development began with Frederick Winslow Taylor in the 1880s and 1890s within the manufacturing industries. Although scientific management as a distinct theory or school of thought was obsolete by the 1930s, most of its themes are still important parts of industrial engineering and management today. These include analysis; synthesis; logic; rationality; empiricism; work ethic; efficiency and elimination of waste; standardization of best practices; disdain for tradition preserved merely for its own sake or merely to protect the social status of particular workers with particular skill sets; the transformation of craft production into mass production; and knowledge transfer between workers and from workers into tools, processes, and documentation"; http://en.wikipedia.org/wiki/Scientific_ management.
} 
computer-based configuration for standardization. Here the object is to meet the market forces of individual needs. $^{3}$

Mass customization forms a compromise between highly industrialized manufacturing processes and a customized end-user perspective. Yet, one has to keep in mind that the manufacturing processes and products are still very standardized in a number of ways. To some extent mass customization can be regarded as based on standardization of processes instead of products. In this interpretation, the products are no longer off-the-shelf items, but now liberated from a purely mechanistic logic to also include variation in product properties, flexibility in design solutions and development of added services and branding strategies linked to the product.

This way of thinking in contemporary production industry leads to new sorts of products and supplies that challenge the traditional or existing premises of the construction industry, which is permeated by the contracting culture of procurement and tendering.

However, in the building industry a quite flexible - but as mentioned earlier by no means efficient - production system already exists and the products and construction solutions (designs) are for the most part individually customized. As such, the building industry is still very dominated by the Custom Made. This is not in order to fulfill the needs of the end-user defined by an individualized market, but rather to satisfy a particular client. As such, this notion is much in line with an architectural rationale - which is oriented towards the specific project and a market rooted in specified and cultural values.

The idea of mass customization in regard to the building industry is however still interesting, where the manufacturers of consumer goods seek to individualize the mass produced, the objective of the building industry will be to mass-produce the individualized as stated by Beim, Nielsen and Vibæk (2010). By adopting the concept of mass customization, although from the side of the unique - the building industry becomes more aligned with the production industry, both in terms of manufacturing, quality control and business strategies. From an architectural point of view, it is particularly important to focus on the flexibility of digitalized industrial manufacturing, the quality improvement, and the end-user perspective, when taking part in this inevitable development of the building industry. Kieran and Timberlake (2004) have described how the architectural project design can benefit if architects take on the responsibility of developing the building industry.

\subsection{System products and integrated product deliveries - a new sort of building industry?}

Mass customization is also conceptually applied when developing integrated product deliveries (IPD), which refer to a new industrialized article of trade that can be identified as, 'a multi-technological complex part of a building' that can 'be configured and customized' to a specific construction project. It is furthermore 'developed in a separate product development process based on the principles of integrated product development' (Fig. 2). In it's actually produced and specifically customized state and when delivered to a customer this building assembly becomes an integrated product delivery that - as a kind of super level - also can include 'marketing, shipment and servicing' as described by Mikkelsen, Beim, Hvam \& Tølle (2005). A building element or construction system based on Integrated Product Delivery (IPD), holds a well integrated, structured organization of knowledge disciplines and systemized

\footnotetext{
3"Consumerism is a social and economic order that is based on the systematic creation and fostering of a desire to purchase goods and services in ever greater amounts. In economics, consumerism refers to economic policies placing emphasis on consumption. In an abstract sense, it is the belief that the free choice of consumers should dictate the economic structure of a society. The term "consumerism" was first used in 1915 to refer to 'advocacy of the rights and interests of consumers"'. http://en.wikipedia.org/wiki/Consumerism.
} 


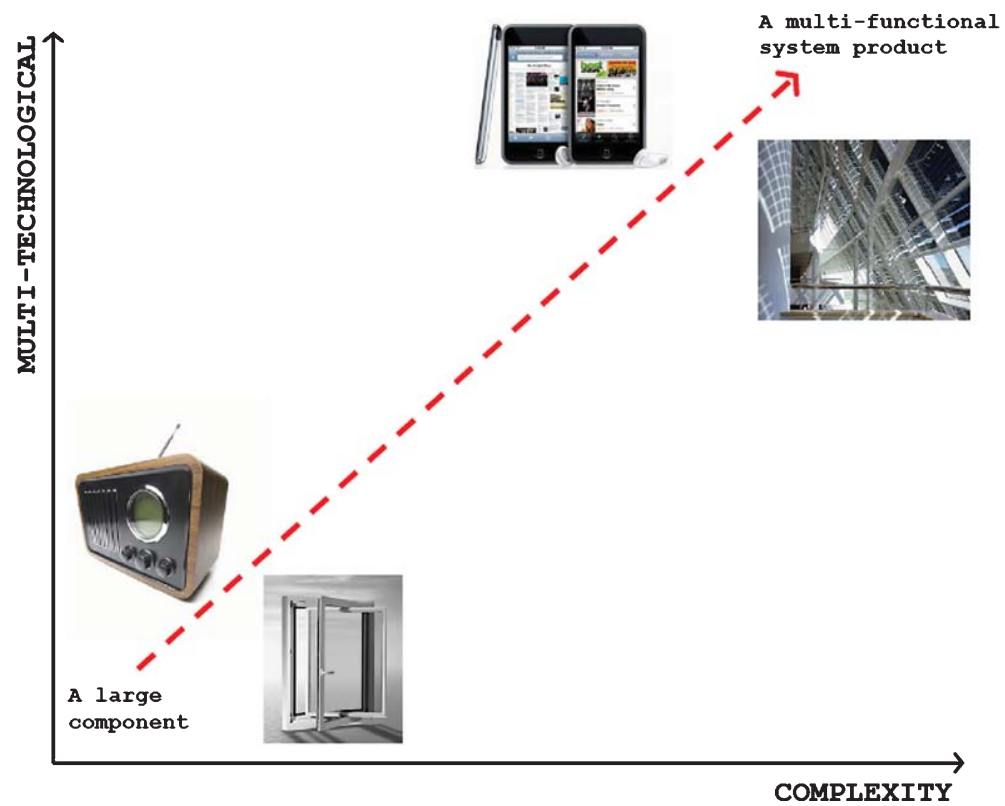

Fig. 2. The development towards an Integrated Product Delivery. Illustrated by an I-phone and an intelligent façade system.

processes, it is supported by use-driven innovation, and have service elements and business strategies incorporated.

To sum up:

- A system product is a complex (sub-)system in buildings developed as finished product

- A system product is made for mass customization and thus to a certain extend it can be fitted to individual needs and demands. Customization is prepared by computer-based configuration!

- A system product is an industrialized product - developed product-wise and process-wise via an industrial process from configuration through use to facility management

- An integrated product delivery is a customized delivery of a configured system product for a building

- A system product is a thoroughly designed and quality proofed product!

However, where is the challenge in order to incorporate this advanced technological aim into the building industry? It is curious to see that building systems of today for the most part are conceptualized as whole units or modules (physical) - seen as large parts of the buildings physical structure; e.g. facade elements, ceiling panels, load bearing constructions. The aim when developing a system product for an integrated product delivery is to raise the system product to a higher level of functionality, which is integrating several features or performances. These could be developed for indoor climate systems, energy supply systems, laboratory spaces or bathroom pods.

It is important to understand that this is a new way to develop products and systems for buildings and it relies on functional thinking and connection to complex systems. It is based on new product ideas that are created in the dialogue between different professions/disciplines, where the challenge is to create coherence between various fields of knowledge, technologies and building systems. Part 
of the objective is to develop new knowledge based products that can be sold at an international market. Mikkelsen, Beim, Hvam \& Tølle (2005).

\subsection{Product development - beyond the development of the product?}

The American economist Joseph Pine (1992/2007) and the German/American professor in business theory, Frank Piller have both in various ways offered a number of theoretical models within this field of business management theory. The latter is a central figure in the "International Institute on Mass Customization and Personalization" (IIMCP or short: MCP institute). It is a society to provide a platform for interaction between researchers and practitioners on mass customization, personalization and related issues.

The proposed models sustain a development towards business strategies that draw upon the (end) users as creators for innovation. The theoretical framework is primarily meant for the progression of economic value in the industry of consumer goods, but similar ideas are now also being picked up and adjusted to the specific features of the building industry in research environments of construction management and architectural management.

In order to explain Pines ideas further they are tested on a VELUX skylight window system (Fig. 3). Where the traditional building industry, producing building components and construction elements, usually focus at the first two levels of commodities and goods in terms of what to offer to the client, the manufacturer of an integrated product delivery offers a customized delivery of additional levels of product development. These can be purchased supplementary and will be delivered as unique addons, provided by a specific sales organization and delivered as a 'special' delivery. In the case of the VELUX skylight window, it can be particular services (e.g. extended warranties, maintenance, facility management etc.), developed and customized according to the clients needs. Similarly, a specific experience of daylight can be offered by a customized combination of solutions and services. The

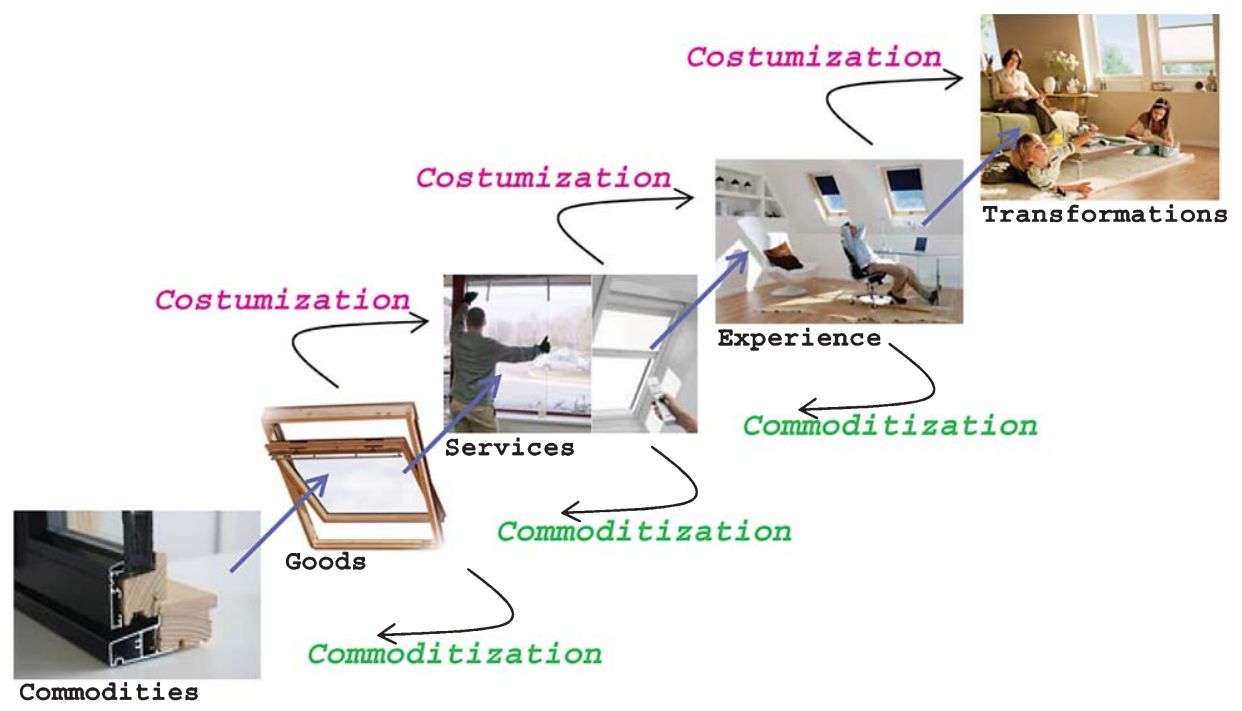

Model of commoditization (Joseph Pine II, 2000), tested on VELUX skylight windows

Fig. 3. Model for customization and commoditization, by Joseph Pine, 2000 tested on VELUX skylight window systems. 
final level of customization is directed towards transformation. This can be new ways of using the architectural space, provided by a customized series of former deliveries.

Another part of Pines theory described in Fig. 3 shows how these various levels of output can be transformed into commoditization. These can developed closely related to the integrated product delivery or can be developed as new separate supplies. From the experience level, one can develop lifestyle packages; from the service level one could develop special packages combining e.g. warranties and maintenance.

At the level of goods, the commoditization could be the branding of the product as maybe highly sustainable, long lasting materials, which offers the right sentiment about the product. In conclusion, it requires creative imagination and synthesis thinking to develop the product beyond the development of the product.

\subsection{Translation of industrialized processes into tectonic design strategies in architecture}

Fredrik Nilsson a Professor in architecture at Chalmers, and Head of R\&D at White Architects, which is Sweden's largest Architectural office, has researched into building construction and design procedures in architecture in great depth and how these are being influenced by contemporary industrialized processes and manufacturing. Nilsson (2007) has put forward the argument that industrialized architecture can be seen as a tectonic strategy: "Prefabricated elements can today be made optimal and unique, following the lines of forces in construction and having other geometries, opening up possibilities for new architectural expressions as well as more economical, resource efficient and sustainable building. Here are new possibilities for interesting development of different tectonic expressions in architecture." (2007, pp. 2-3). In addition to this, Nilsson points out the tectonic discipline as a useful way to approach the new challenges of the building industry. In this article described as, resource management, industrialized processes and manufacturing, integrated product deliveries, commercialization of building from commodity to architectural experience. As a reply to these serious challenges, Nilsson highlights an argument by the American architectural theoretician, Kenneth Frampton, which is presented in his book: Studies in Tectonic Culture: The Poetics of Construction in Nineteenth and Twentieth Century Architecture: "[... ] our built environment is produced in interplay of three aspects - topos, place; typos, building type; and the tectonic. The tectonic is according to Frampton the aspect best suited to counter present tendencies to legitimize architecture in discourses outside its own discipline" (1995).

As stated in the introduction of this article - tectonic thinking concerns the materials/resources and their use in an architectural creative context. By giving emphasis to how buildings are made and how this making is detectable in the building, tectonic thinking can be pushed forward as a way to challenge the standardization and commodification of building production. This understanding has also been pushed forward by Torben Dam (2007) a landscape researcher, who has looked into how tectonics make meaning in landscape architecture. Here 'the making' is specifically related to site and context.

In many ways, contemporary industrialized manufacturing can be compared to some of the characteristics in tectonic thinking such as: Resource thinking, process thinking, and system thinking. Each dimension considered from a synthesis perspective. As such it also forms a mode of practice or conduct that is embedded in architectural making.

Tectonic thinking can be defined as a key that both hold on to the essential nature of architectural making, as well as it provides a 'systemized language' of principles by which architects can specify 
technical knowledge used for technology transfer and hereby for developing new products for the building industry.

A new attempt to translate and conceptualize industrialized building components and processes into tectonic design strategies in architecture and for the building industry, has been developed in the industrial PhD-study of Søren Nielsen, who is architects and partner in the Danish architectural firm, Vandkunsten. In this study he focuses on: Adaptive architecture and sustainability: Adaptability as tectonic strategy. As part of his case study for a new façade cladding system that can be re-used, he has tried to develop a design/construction strategy for Design for Disassembly (DfD). This study has developed into a sort of language or rather syntax for a construction of knowledge relating to three stages of production:

1. Production of systemized technical protocols for programmatic purposes, consisting of diagrams

2. Production of experimental knowledge through implementation of technical protocols, resulting in drawings, models, prototypes and buildings

3. Production of analytical diagrams from case-studies resulting in documentation diagrams and pictograms

The following three diagrams are results of the first and third stage of production. They show how Søren Nielsen (2011)systematically maps the principles of tectonic articulation and the technical

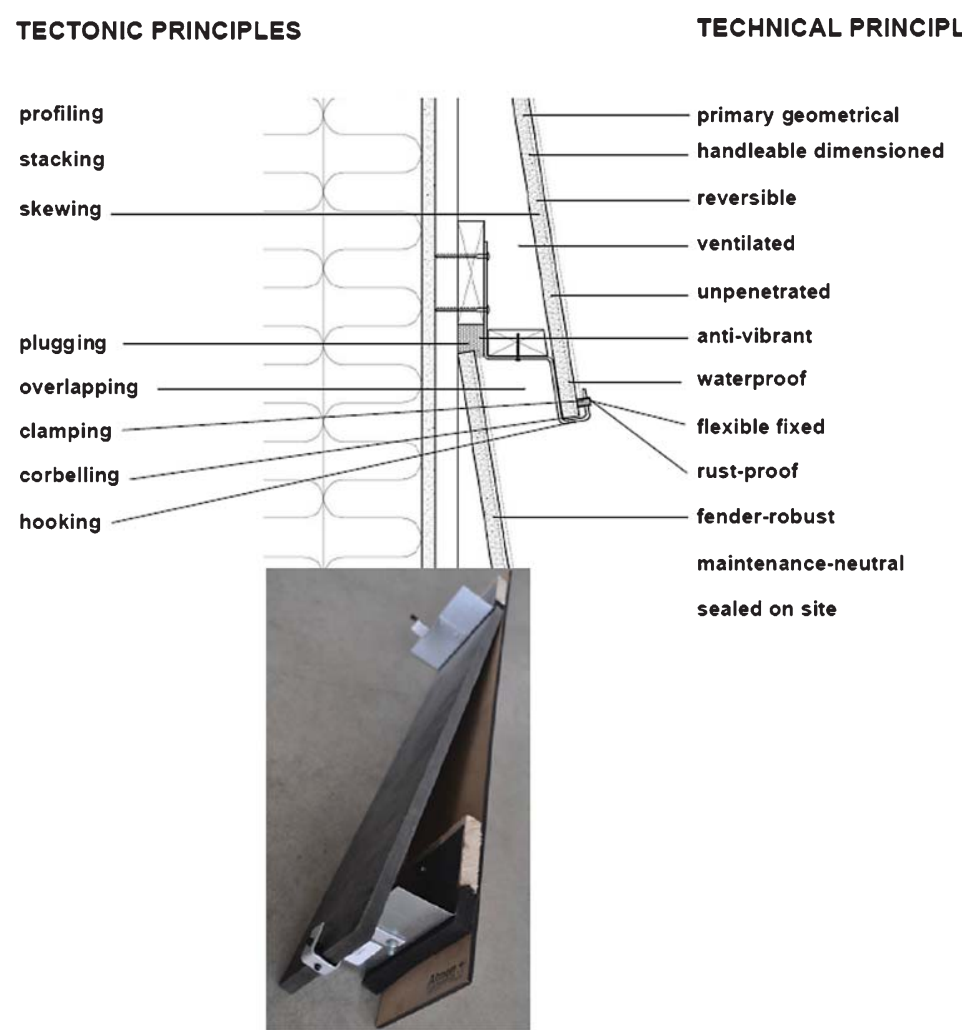

Fig. 4. Diagram showing the tectonic and technical principles of a particular case study; drawing and prototype of a assembling detail for a reversible façade cladding panel, by Søren Nielsen, Vandkunsten Architects. 


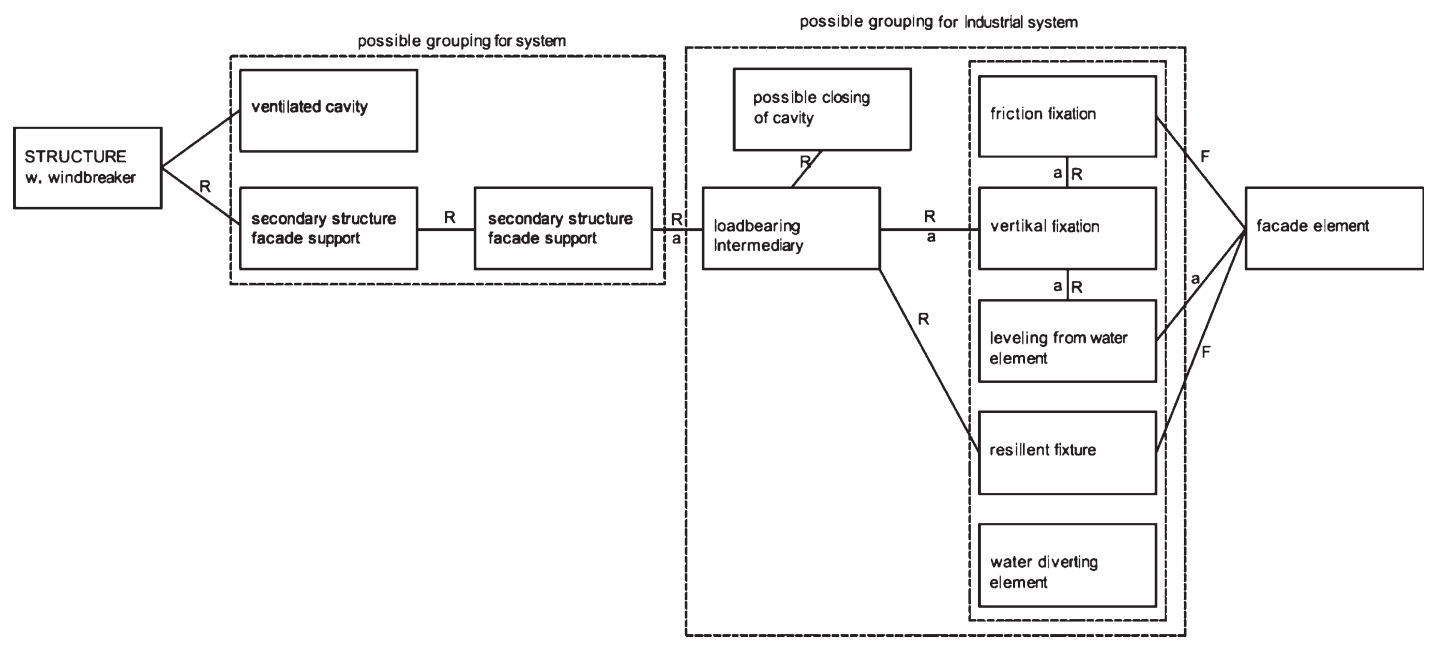

Fig. 5. Diagram showing the correlation between technical solutions, by Søren Nielsen, Vandkunsten Architects.

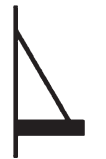

ํㅗํ.

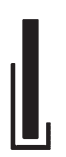

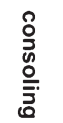

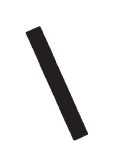

章

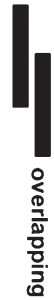

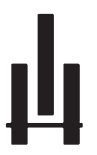

을

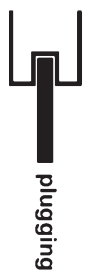

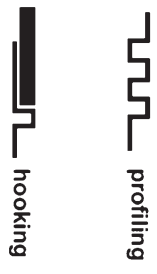

Fig. 6. Pictogram showing tectonic articulation, by Søren Nielsen, Vandkunsten Architects.

principles in protocols for empiric analysis (Fig. 4). By scanning a number of cases in a matrix for tectonic and technical principles, he provides a method to identify the relations between the different principles. He describes the scanning process as generative or self-supplying because the taxonomy of building principles is generated as a gradually more precise tool when utilized.

A central part of Søren Nielsen's work is to extract the tectonic and technical principles from highly situated and specified solutions into more generic data. Nielsen (2011) describes the extracting processes as following: "Diagrammatic representation of architectural solutions: In technical diagrams a building, its part and details, can be dissolved into a number of singular variables with a general relevance for all similar operations. The diagram accounts for and documents programmatic requests, but reveals nothing about the tectonic articulation. However, the tectonic articulations can be identified as form-generating types of phenomena, which can be illustrated in pictograms and perhaps other abstract representation. The very relationship between tectonic articulation and technical principles remains situated, embedded in the material evidence of the practical cases".

By a systematic and visual approach as illustrated in Figs. 5, 6, Søren Nielsen offers a transparent methodology, which shows how to develop various tectonic features of a specific construction solutions or architectural designs. The diagrams make it possible to follow the different principle levels or tracks of design decisions; also, they provide a clear (tectonic) terminology for communication 
(technology transfer) and dissemination of a product or construction detail to other disciplines within the building industry.

The future demands of industrialized architecture - concluding arguments.

A fully developed industrialized architecture may help to transfer knowledge though systematic product development, as proposed in the models of Integrated Product Deliveries (IPD).

A fully developed industrialized architecture ought to be based on tectonic principles, focusing on the interplay of 'construction and construing'.

- at product level of building components focusing on assembly of various elements

- at system level focusing on integration of various systems

- at the level of all-encompassing systems focusing on conceptualizing of various building constructions/designs (eg. light weight wooden elements)

A fully developed industrialized architecture will have to be based on sufficient numbers of products of high quality and it requires a great variety of suppliers offering a higher level of system solutions. If so, it may create new international markets for integrated products and systems.

A fully developed industrialized architecture may help to direct and optimize our use of resources - in terms of Design for Disassembly (DfD) and conceptualized as Cradle to Cradle in order to reach sustainable solutions.

\section{Acknowledgments}

I want to thank Søren Nielsen, Architect, and Partner of Vandkunsten Architects, who in his present research into design strategies for sustainable construction - in this article also called tectonic design strategies - has inspired to this article and enriched the scientific field of architecture with vital knowledge.

Also, I want to thank Kasper Sanchez Vibæk, Associate Professor in CINARK and former colleague, for having developed the topic of Integrated Product Deliveries from an architectural point of view by doing the hard work of challenging its rigid nature by scientific means instead of ignoring it due to academic fear or prejudice.

\section{References}

Beim A., Nielsen J., \& Vibæk K. S. (2010). Three Ways of Assembling a House, CINARK RESEARCH, The Royal Danish Academy of Fine Arts School of Architecture Publishers, 2010, 52

Dam T. (2007). Conference paper: Does tectonics make meaning in landscape architecture, International Conference: Tectonics Making Meaning, university of Eindhoven, Dec.

Gilmore, J. H., \& Pine J. B. (2007). Authenticity: What Consumers Really Want, Harvard Business Review Press.

Kieran, S., \& Timberlake J. (2004). Refabricating Architecture: How Manufacturing Methodologies are Poised to Transform Building Construction, McGraw Hill Co., NY.

Mikkelsen, H., Beim A., Hvam L., \& Tølle M. (2005). SELIA - Systemleveranceri Byggeriet - en udredning til arbejdsbrug (SELIA - Integrated Product Deliveries in construction - a survey for project development); DTU, Denmark's Technical University, Institute of production \& Management.

Nielsen, S. (2011). 'Adaptability as a tectonic strategy', IN; The Role of Material Evidence in Architectural Research: Drawings, Models, Experiments. Thomsen, R. M. (ed.) \& Beim A. (ed.), The Royal Danish Academy of Fine Arts, Schools of Architecture, Design and Conservation.

Nilsson F. (2007). New technology, new tectonics? - on architectural and structural expressions with digital tools, International Conference: Tectonics Making Meaning, University of Eindhoven. 
Pine J. B. (1992). Mass Customization: The New Frontier in Business Competition, Harvard Business Review.

Strike, J. (1991). Construction into Design: The Influence of new methods of construction on architectural design 1690 - 1990 , ButterworthHeinemann Ltd., Oxford. 